\title{
La culture scientifique Un débat mis en avant par la SFP
}

Les débats sur la culture resurgissent régulièrement comme un des enjeux - mineurs - lors d'élections politiques. C'est ainsi qu'à l'occasion de la campagne présidentielle de 2012, Martine Aubry a publié une opinion dans Le Monde du 26 juillet 2011 sur l'importance de la culture dans la vie des Français. En d'autres temps, il n'aurait pas été besoin de rappeler que la culture scientifique est une part importante de la culture générale. Mais elle apparaît comme une grande oubliée de la campagne qui s'annonce et des programmes des candidats à l'élection présidentielle. Et pourtant la culture scientifique est nécessaire à la formation des citoyens français, vu le rôle majeur joué par les sciences et techniques dans le monde moderne. Elle doit permettre au citoyen de porter un regard critique et d'émettre des jugements raisonnés sur les débats de fond traversant la société actuelle. Une récente enquête IPSOS [1], sur «Les Français et la science », souligne d'ailleurs la forte confiance de nos concitoyens dans la science pour apporter des solutions aux problèmes rencontrés dans le monde et pour améliorer leur vie, mais que leur confiance dans les scientifiques varie fortement en fonction du domaine et du risque qui lui est associé.

Rappelons la définition de la culture scientifique que donnait I'UNESCO en 1993 :

"La culture scientifique, c'est un ensemble de capacités, de connaissances et de savoir-faire spécifiques s'accompagnant d'un regard critique sur la science et ses rapports avec d'autres champs de l'activité humaine, y compris la technologie. Cette forme de culture est indispensable dans toute société si l'on veut vraiment aider les individus à savoir maitriser le cours des choses, améliorer la qualité de vie et leur proposer un avenir viable. "

À partir de cette définition, on peut proposer deux types d'actions complémentaires pour les acteurs de la diffusion de la culture scientifique, l'une à l'École envers les jeunes en formation et la seconde en direction du grand public et du citoyen adulte. L'article publié dans ce numéro de Reflets de la physique (pp. 24-26) montre que le système scolaire français ne répond pas à ce besoin, alors que des efforts sont faits par différentes associations (Main à la pâte, sociétés savantes, CCSTI...) intervenant dans les écoles " pour passer le message ». Le moment est peut-être venu d'articuler toutes ces initiatives pour essayer de les généraliser. Le peu d'intérêt de nos gouvernants pour la culture scientifique (voir la disparition de la cellule correspondante au ministère de l'Enseignement supérieur et de la Recherche, et l'absence déjà notée de références à cette culture dans les projets des candidats) rend de telles initiatives urgentes.

La Société Française de Physique a conscience de ces enjeux et y joue son rôle, en particulier par l'intermédiaire de deux de ses commissions, la Commission Enseignement et la Commission Culture Scientifique. Elle a ainsi publié une tribune intitulée "La culture, ce sont les arts mais aussi les sciences " dans la rubrique "Idées " du Monde électronique du 5 août 2011 [2]. Elle a attribué le prix Jean Perrin 2010 (prix de la popularisation de la Science) à Mathieu Vidard pour son émission « La tête au carré » sur France Inter. Et, à l'occasion de la campagne pour les présidentielles, elle se propose d'envoyer à tous les candidats une lettre leur demandant quelle sera leur politique en matière de culture scientifique, d'enseignement scientifique et de recherche universitaire. Les réponses seront publiées dans Reflets de la physique.

La SFP organise aussi au Palais de la découverte, le 9 janvier 2012, en partenariat avec I'AJSPI (Association des Journalistes scientifiques de la Presse d'Information), une journée de discussions et débats : "Science et Médias, mieux travailler ensemble ». Cette journée a pour objectif de réfléchir à une amélioration de l'information scientifique dans les médias grand public.

Martial Ducloy ${ }^{(a)}$ et Daniel Bideau ${ }^{(b)}$

(a) Président de la Société Française de Physique (SFP)

(b) Président de la Commission Culture scientifique de la SFP

[1] www.ipsos.fr/sites/default/files/attachments/les_francais_et_la_science.pdf

[2] www.lemonde.fr/idees/article/2011/08/05/la-culture-ce-sont-les-arts-mais-aussi-les-sciences_1556293_3232.html 